\title{
Decision-Making Techniques using LSTM on Antam Mining Shares before and during the COVID-19 Pandemic in Indonesia
}

\author{
Ahmad Kamal Badri' ${ }^{1}$, Jerry Heikal ${ }^{2}$, Yochebed Anggraini Terah ${ }^{3}$, Deden Roni Nurjaman ${ }^{4}$ \\ 1,2University of Bakrie \\ 3,4 University of Raharja \\ 1,2JI. Raya Palka No.Km 3, Panancangan, Kec. Cipocok Jaya, Serang, Banten 42124 \\ 3,4Modern, Jl. Jenderal Sudirman No.40, RT.002/RW.006, Cikokol, Kec. Tangerang, Kota \\ Tangerang, Banten 15117 \\ e-mail: achmadkamalbadri@gmail.com ${ }^{1}$, jerry.heikal@bakrie.ac.id² ${ }^{2}$,yochebed@raharja.info ${ }^{3}$, \\ deden.roni@raharja.info ${ }^{4}$
}

To cite this document :

Badri, A.K., Heikal, J., Terah, Y.A., \& Nurjaman, D.R. (2022). Decision-Making Techniques using LSTM on Antam Mining Shares before and during the COVID-19 Pandemic in Indonesia. Aptisi Transactions on Management (ATM), 6(2), 167-180.

DOI :

https://doi.org/10.33050/atm.v6i2.1776

\begin{abstract}
Stocks, apart from having volatile and chaotic characteristics, also have various kinds of noise, non-linear and non-stationary movements, making them difficult to predict accurately. Therefore, the risk of investing in stocks depends on the skills of investors or traders in making judgments and decisions. This study aims to use Long Short-Term Memory (LSTM) as a decision-making technique with historical stock prices as the sole predictor, then implement it in conditions before and during the COVID-19 pandemic. The study results concluded that Long Short-Term Memory (LSTM) could be used as a decision-making technique in conditions before and during the COVID-19 pandemic with historical price inputs as the sole predictor. Based on the research that has been done, the following conclusions can be drawn: The LSTM model can predict stock prices well using historical stock prices as the sole predictor. The LSTM model can be used as a trading decision-making technique for day traders. The risk of stock prediction using the LSTM method in 2019 before the COVID pandemic was proven to be lower than in 2020 during the COVID pandemic. For further research, researchers can conduct more in-depth research on the risk criteria for making trading decisions as an essential reference that can be used to select the LSTM model.
\end{abstract}

Keywords: Stocks, COVID-19, Historical Stock Prices, LSTM, Decision Making Technique

\section{Introduction}

Investing and trading stocks is an activity that can provide significant profits in a short duration but has a high risk. Stocks, apart from having volatile and chaotic characteristics, also have various kinds of noise, non-linear and non-stationary movements, making them difficult to predict accurately. [1]-[4]. The risk of investing in stocks depends on the ability of investors to make judgments and make decisions. Not everyone can be a winner in stock trading because stock trading is an activity to make money from other traders [5]. the attractiveness of stock investment did not decrease and even tended to increase in the conditions of the COVID-19 pandemic. On the contrary, the COVID-19 pandemic has become a stimulus for increased new investors' stock markets [6]. 
Indonesia first confirmed COVID-19 entry on March 2, 2020, and officially declared it as a national disaster on April 13, 2020 [7], [8]. The pandemic in Indonesia contributed to the fall in the IHSG, which touched the lowest level of Rp. 3,937.63 on March 24, 2020, and precisely a year after COVID-19 was confirmed to enter Indonesia, the IHSG managed to strengthen to the level of Rp. 6,359.21. The online news portal kontan.co.id launched, the shares of the gold mining issuer PT. Aneka Tambang with code ANTM strengthened to $374.78 \%$ during the period March 2, 2020, until March 2, 2021. The increase in ANTM has benefited from the rise in the gold price, which is increasingly attractive during the COVID-19 pandemic as a choice of hedging asset or safe haven [9].

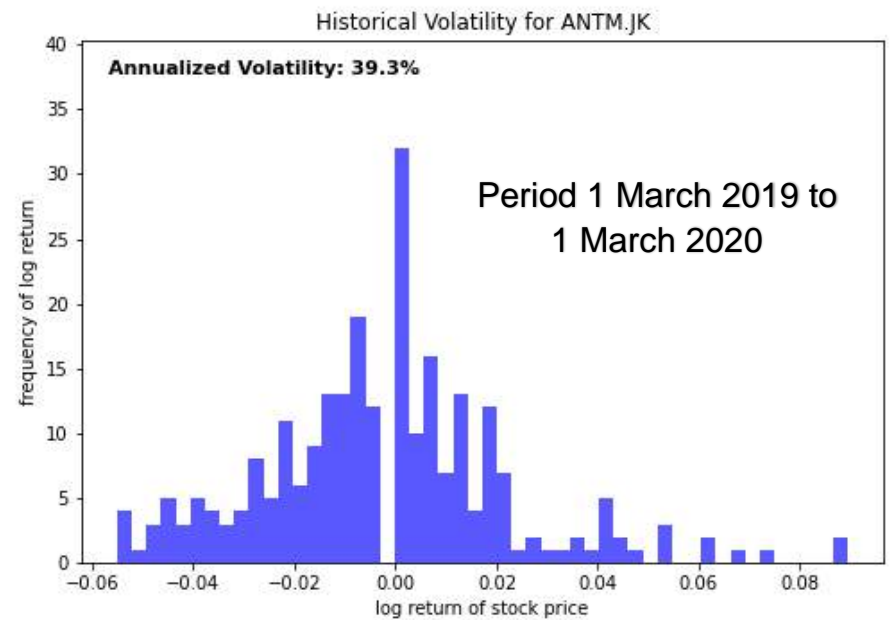

Figure 1 ANTM Volatility Period 1 March 2019 to 1 March 2020

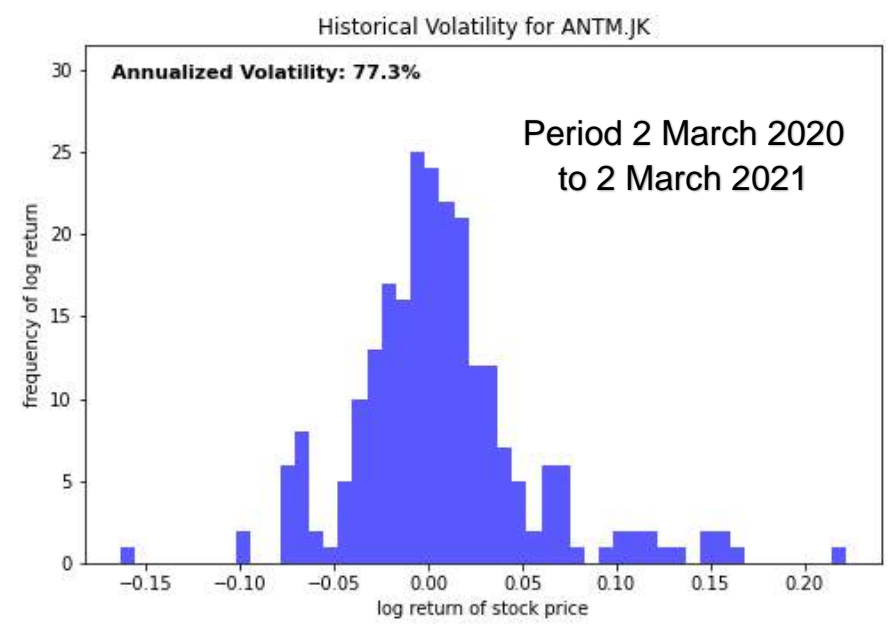

Figure 2 ANTM Volatility Period 2 March 2020 to 2 March 2021

Figure 1 and 2 shows the percentage level of volatility a year before COVID-19 pandemic and a year during the COVID-19 pandemic in ANTM shares. For example, a year before the COVID-19 pandemic, ANTM's stock had a volatility level of $39.3 \%$ and almost doubled or $38 \%$ during the COVID-19 pandemic to $77.3 \%$. This phenomenon illustrates the increase in the value of ANTM's shares at the level of volatility during the COVID-19 pandemic compared to the volatility before the COVID-19 pandemic.

Volatility is a call today trading. To make a profit, day traders rely on the volatility of stocks and take advantage of fluctuations in stock prices in the market. Day traders are very fond of liquid stocks, making it possible to maneuver in and out without affecting the stock price [10]. However, the higher the volatility, the higher the risk in predicting stock prices [11]. This event makes making the right decision even more difficult. 
Based on the press release of the Indonesia Stock Exchange (IDX) No. PR-014/KPEISPE/1220, throughout 2020, there was an increase in the number of investors in the Indonesian Capital Market, which reached 3.87 million Single Investor Identification (SID), or up 56 percent from 2019. The number of daily investors increased by 94 thousand or 73 percent [12]. The COVID-19 pandemic has become a stimulus for increasing the number of new investors in the stock market.

The phenomenon of the increase in the number of stock investors during the COVID19 pandemic requires vigilance, especially for investors or day traders who have just entered the world of the stock market, mainly due to the rise of the stock pump phenomenon [13]. Investing requires deep analysis and not acting impulsively.

Pompom is an attempt to form opinions or lead opinions on fried stocks regulated by the dealer [14]. [15] explains, fried dealers regulate price movements by manipulating price and volume. Its characteristics are, this party relies heavily on inside information, spreads rumors, and carries out its buying and selling activities to lure transactions; a suddenly deserted market is a sign of a completed project. Unlike fried dealers, amateur dealers are novice players who try to imitate the dealer's activities for personal gain. Its activities are trial and error, usually carried out on issuers with small capitalization. So, the pompom phenomenon is related to the bookie and emphasizes the importance of prudence in processing information in making stock transaction decisions.

[16] research on behavioral biases in investment decision-making shows that various biases extensively influence individual investors' behavior. Overconfidence and herding bias have a significant positive impact on investment decisions. [16] conclude that individual investors have limited knowledge and are more prone to making psychological errors, indicating the overconfidence, anchoring, disposition effect, and herding behavioral biases on personal investment decisions.

Stocks are challenging to predict because of the noisy, non-stationary, uncertain, and time-varying nature of stock data [17], [18]. However, some researchers argue that stock price unpredictableness is not entirely random and can be predicted. This assumption is based on chaos theory which tries to understand and explain the nature of stocks where the random behavior of stock data can be predicted from its unpredictable nature so that chaos theory can be used as an appropriate part of knowledge to find order in disorder [19]-[21].

Machine Learning (ML) is a subset of Artificial Intelligence (Al) which has increased in popularity in the investment industry in recent years as a technical analysis tool in stock forecasting. If technical analysis functions as a trading strategy for entry and exit, ML can affirm stock options. One of those machine learning is Long Short-Term Memory (LSTM). LSTM is a variation of Recurrent Neural Networks (RNN), which is dynamic and allows Machine Learning (ML) modeling on data that has chaotic characteristics so that it can help make decisions based on past price behavior patterns [3], [22]-[24]. Initially, using Al was only done by large companies, but now Al in trading has become mainstream for companies or individuals [21].

Murphy [25] argues that all factors that influence prices will be truly reflected in prices, where price and transaction volume are the basis for technical analysis. However, Murphy's opinion contradicts the opinion of Fama based on the theory of random walks, which implies technical analysis actions based on stock price procedures as useless activities and stock prices categorized as noise. The random walk theory implies that changes in stock prices (the difference in the cost of securities from one period to another) maintain the same probability distribution and are independent of each other; therefore, stock price movements in the past cannot be used to predict future movements [26].

Long Short-Term Memory (LSTM) as part of Machine Learning (ML) is a subset of Artificial Intelligence (Al). In recent years, Al has increased in popularity in the investment industry as a technical, analytical tool in stock forecasting. If technical analysis functions as a trading strategy for entry and exit, Machine Learning (ML) LSTM model can act as affirmative support for stock options. However, [27] research concludes that short-term predictability and forecast are impossible; the more time elapses between the appearance of choice and its consequences, the more certain it is for individuals to assume that their decisions must be made under ambiguous conditions circumstances.

Based on the explanation above, this research aims to:

1. To determine whether historical stock prices can be used as a single predictor in predicting stock prices using the LSTM method 
2. To find out whether the LSTM method can be used as a decision-making technique for buying and selling shares of daily traders.

3. To determine whether the risk of stock prediction using the LSTM method in 2019 before the COVID pandemic was lower than in 2020 during the COVID pandemic.

\section{Research Method}

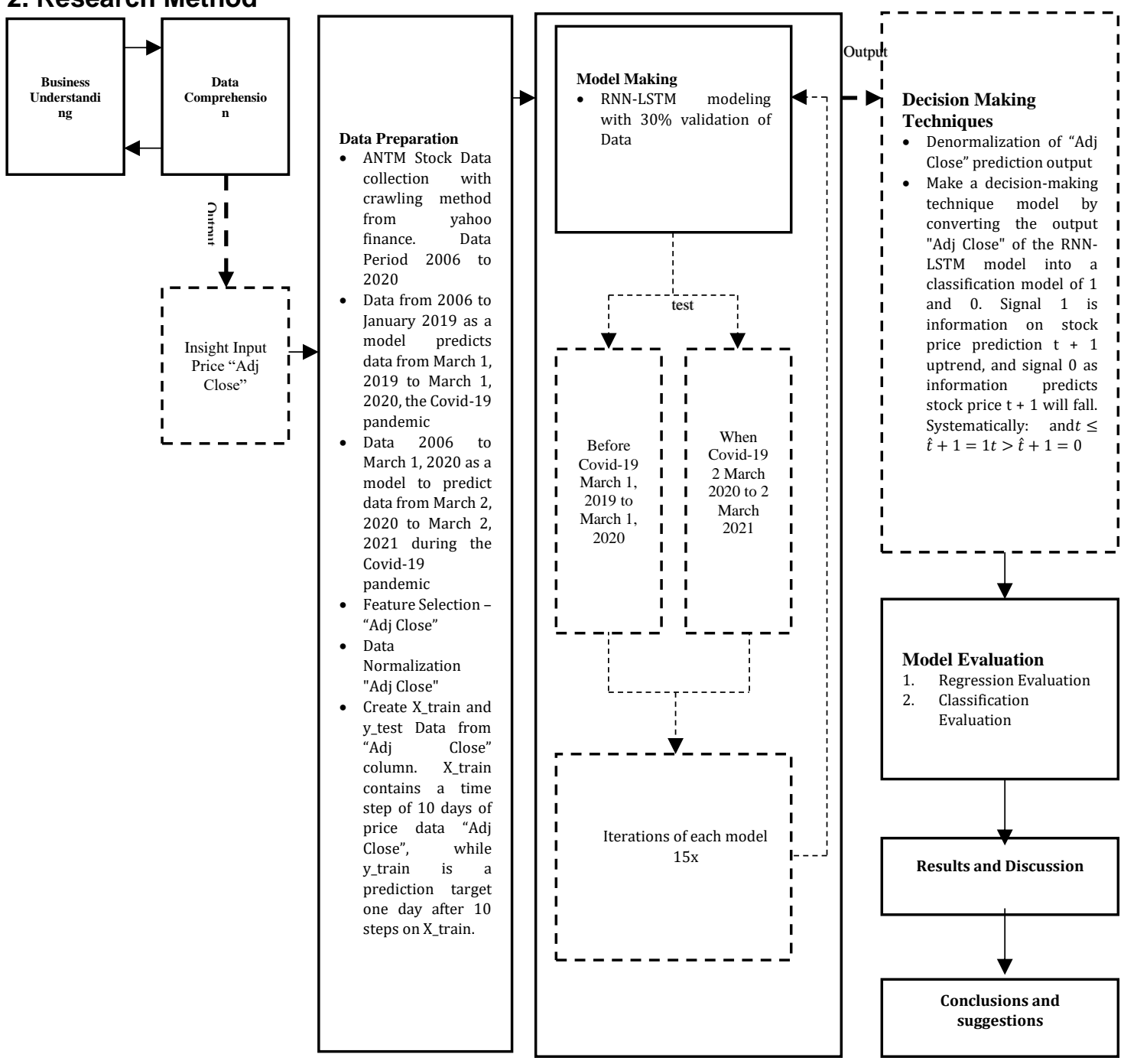

Figure 3 Experimental Flow Model

\subsection{Types of Research}

The research method used in this study is quantitative method by combining a sequential model (hybrid model). Empirically, this research is divided into several model as follows:

- ANTM's stock price prediction uses historical stock price data by selecting the "Adj Close" feature based on the range $t-10$ to $t$ as a predictor using the RNN-LSTM model. Predictions are made from March 1, 2019 to March 1, 2020 before COVID 19 and March 2, 2020 to March 2, 2021 during the COVID 19 pandemic. The prediction method is by predicting the price the next day, $\mathrm{t}+1$.

- Perform classification modelling from the predicted output of the RNN-LSTM model as a recommendation for traders' strategy decision-making in trading signals 1 and 0.1 as a signal tomorrow the stock price will go up, while 0 as a signal that tomorrow price will go down.

\subsection{Understanding Business and Data}

The author uses the literature study method to understand the business and the data needed in this study. A literature study is used to examine the required literature. 


\subsection{Method of collecting data}

The historical sample of ANTM's stock price data was obtained from yahoo finance with the crawling method in the data range from 2006 to March 2, 2021. The data obtained contains the date, high, low, open, close, adjusted close, and volume features. The feature input in this study is adjusted close, with the consideration that the adjusted close feature is the closing price of the stock that has been adjusted to reflect the stock value [28]

The data is divided into training data and test/validation data to be used as a stock predicting model. Data from 2006 to February 2, 2019, predicts stocks from March 1, 2019 to March 1, 2020 before the COVID-19 pandemic. The data from 2006 to March 1, 2020 predicts stocks from March 2, 2020 to March 2, 2021 during the COVID pandemic.

\begin{tabular}{|c|lll|l|l|l|}
\hline Date & Open & High & Low & Close & Adj Close & Volume \\
\hline $\mathbf{1 / 2 / 2 0 0 6}$ & 604.78 & 608.98 & 600.58 & 604.78 & 423.20 & $6,229,338.00$ \\
\hline $\mathbf{1 / 3 / 2 0 0 6}$ & 608.98 & 608.98 & 587.98 & 592.18 & 414.38 & $33,712,238.00$ \\
\hline $\mathbf{1 / 4 / 2 0 0 6}$ & 608.98 & 621.58 & 604.78 & 621.58 & 434.95 & $57,733,733.00$ \\
\hline $\mathbf{1 / 5 / 2 0 0 6}$ & 625.78 & 655.18 & 625.78 & 650.98 & 455.53 & $78,502,163.00$ \\
\hline
\end{tabular}

Table 1 Sample Historical Data

\subsection{Data Preparation}

Normalization is done to make the values in the data consistent and increase the level of accuracy. Normalization of data using MinMax Scaler contained in the sklearn library. The data is normalized to a range between 0 to 1 using the formula:

$$
X_{\text {new }}=\left(X_{\text {old }}-X_{\min }\right)\left(X_{\max }-X_{\text {min }}\right)-1
$$

\subsection{Creating Training Data}

Create training data by looping using the "Adj Close" column on 2006 to 2018 data and 2006 to 2019 data into numeric form into X_train and y_train. X_train contains a time step of 10 days of price data "Adj Close", while y_train is a prediction target one day after ten steps on $\mathrm{X}$ train.

$$
\begin{gathered}
\text { X_train }=t-10, s d t \\
\text { y_train }=t+1
\end{gathered}
$$

\subsection{RNN-LSTM Modeling}

The RNN-LSTM model in this study is as follows:

model $=$ hard .Sequential ()

model.add $($ LSTM $($ units $=1000$, return_sequences $=$ True , input_shape $=(X$ train.shape[1],1) $))$

model.add(Dropout(0.2))

model. .add $($ LSTM(units $=1000$, return_sequences $=$ false $)$ )

model.add(Dropout(0.2))

\# Output layers

model. add (Dense(units $=10$, activation=tanh))

model.add(Dropout(0.2))

model. add (Dense(units $=1$, activation=tanh))

\# Compiling the RNN-LSTM

model.compile(optimizer ='adam', loss ='mean_squared_error',

metrics=['mean_absolute_percentage_error'])

\# Fitting the model to the Training set

history $=$ model.fit $\left(X \_t r a i n, y \_t r a i n\right.$, epochs $=10$, batch_size $=10$, validation_split $=.30$ ) 


\subsection{Dense Layer}

A dense layer or fully connected layer is a layer where all nodes in the previous layer are connected to all nodes in the next layer. Multiple layers of solid layers form different levels of representation in the data [29]

\subsection{Dropout Layer}

Dropout layers help prevent model overfitting by randomly dropping nodes in the layer. The probability of dropping a node is controlled by a factor that ranges from 0 to 1 . A dropout factor closer to one drops more nodes from the layer. This is a form of regularization that reduces the complexity of the model [29].

\subsection{Activation Function}

The purpose of the activation function is to introduce non-linearity into the output of the neuron. A neural network without an activation function is just a linear regression model. The activation function performs a non-linear transformation into input to learn and perform more complex tasks [30].

The tanh activation function is s-shaped with a range of -1 to 1 [31]. Systematically as follows:

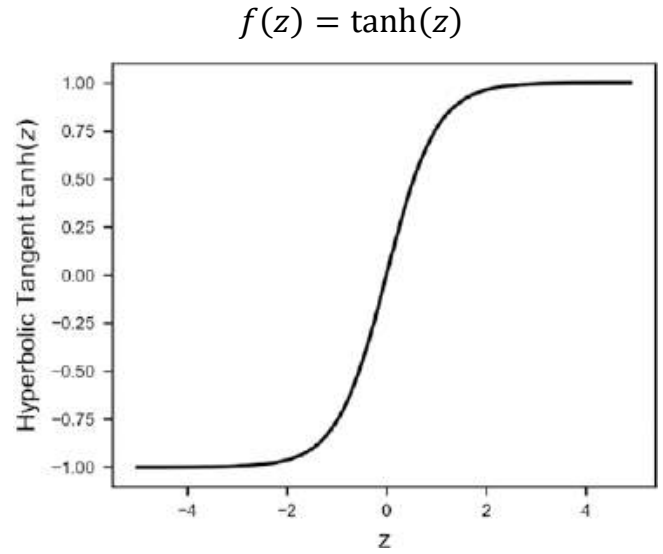

Figure 4 Tanh Activation Function

\subsection{Evaluation Model}

The evaluation model aims to measure the performance of the model. Model performance is a measure of how a machine learning model is evaluated externally. The model must optimize a utility function on the inner side, namely, what functions should be maximized or minimized by the agent, especially at the training stage [32]. The evaluation model in this study is divided into two, regression and classification.

\subsubsection{Regression Evaluation}

The regression evaluation test used the evaluation of Root Mean Squared Error (RMSE), Mean Absolute Error (MAE), Mean Absolute Percentage Error (MAPE), and R2 Score. The lower the RMSE, MAE, and MAPE values, the better the prediction model because the closer it is to the actual value, the smaller the error value. In contrast, the evaluation of the R2 Score value will be better if it is close to 1 or $100 \%$. The value of the R2 Score that reaches a value of 1 or $100 \%$ shows that the model can fully explain stock movements. Regression models with a low R2 Score can be invalid, but the standard of measurement is whether or not a model is valid or not depending on the standard limits used in the model [33].

$$
R M S E=\sqrt{\frac{1}{n} \Sigma e_{t}^{2}} \quad M A E=\frac{1}{n} \sum_{i=1}^{n}\left|\hat{y}_{i}-y_{i}\right| \quad M A P E=\frac{1}{n} \Sigma \frac{\left|e_{t}\right|}{d_{t}}
$$

In investing, [33] explained that the R2 Score is generally defined as the percentage movement of funds or securities that trends in a reference index can explain. R2 Score $100 \%$ means that moves in the index fully explain all security movements (or another dependent variable). If the R2 Score of a model is 0.50 or $50 \%$, then approximately half of the observed variation can be explained by the model inputs. Systematically: 


$$
R 2 \text { Score }=1-\frac{\text { Unexplained Variation }}{\text { Total Variation }}
$$

R2 Score informs the estimate of the relationship between the movement of the dependent variable based on the direction of the independent variable. R2 Score does not tell whether the selected model is good or bad, nor will it tell whether the data and predictions are biased. A high or low R2 score is not necessarily good or bad because it does not indicate the model's reliability or the choice of a suitable regression model. It could be that we get a low R2 Score for a good model, or a high R2 Score for a model that doesn't fit, and vice versa [33]

\subsubsection{Classification Evaluation}

This study converts the output of the RNN-LSTM prediction model from the regression form into a classification model of 1 and 0 . The purpose of the conversion is to see the possibility of prediction results as a support instrument in making trading decisions. For example, signal one as information on stock price prediction $t+1$ uptrend and signal 0 as information predicting stock price $t+1$ will go down. Thus, the prediction output can be evaluated based on the evaluation methods of accuracy, precision, recall, F1 Score, and AUC-ROC. Systematically:

$$
t \leq \hat{t}+1=1 \text { and } t>\hat{t}+1=0
$$

Accuracy informs the model's prediction accuracy value in the form of a ratio of the number of true positive (TP) and true negative (TN) predictions divided by the total number of true positive (TP), true negative (TN), false positive (FP) and false-negative (FN).

$$
\text { Akurasi }=\frac{T P+T N}{T P+T N+F P+F N}
$$

Precision gives the ratio of information to true positive accuracy (TP) divided by the number of TP and FP.

$$
\text { Presisi }=\frac{T P}{T P+F P}
$$

Recall provides information on the ratio of true positives (TP) divided by the number of true positives and true negatives. So, it can be said that recall compares the true positive ratio with all positive predictions to describe sensitivity.

$$
\text { Recall }=\frac{T P}{(T P+F P)}
$$

The F1 score for a class $\mathrm{F} 1 \mathrm{k}$ is defined as the harmonic mean between precision and recall [32]. Systematically:

$$
F 1 \text { Score }=2 \frac{(\text { Recall } x \text { Presisi })}{(\text { Recall }+ \text { Presisi })}
$$

The Receiver Operator Characteristic (ROC) curve is an evaluation metric for binary classification problems. ROC is a probability curve that plots the True Positive Rate (TPR) against the False Positive Rate (FPR) at various threshold values and essentially separates the 'signal' from the 'noise.' Area Under the Curve (AUC) measures the classifier's ability to discriminate between classes and is used as a summary of the ROC curve. The higher the AUC, the better the model's performance in distinguishing positive and negative classes [34].

\section{Literature Review}

\subsection{Long Short-Term Memory (LSTM)}

Long Short-Term Memory (LSTM) is a modified RNN architecture to solve the missing and bursting gradient problem and a training solution with long sequential data and retains memory [35]-[38]. LSTMs are widely used today because of their superior performance in accurately modelling data dependencies in the short and long term. Various previous studies have proven that the performance of RNN-LSTM almost always produces better prediction outputs than other approaches in predicting stock prices [39]-[46].

[36] explained that LSTM worked better than RNN using a cell architecture consisting of 5 different non-linear components, interacting with each other in a certain way. LSTM modifies the internal state of the cell only through linear interactions. LSTM architecture allows information to propagate backward smoothly over time, with a consequent increase in the memory capacity of the cell. LSTM protects and controls information in cells through three gates, 
which are implemented by sigmoid and pointwise multiplication. To maintain the behaviour of each gate, a set of parameters is trained with gradient descent to complete the target task.

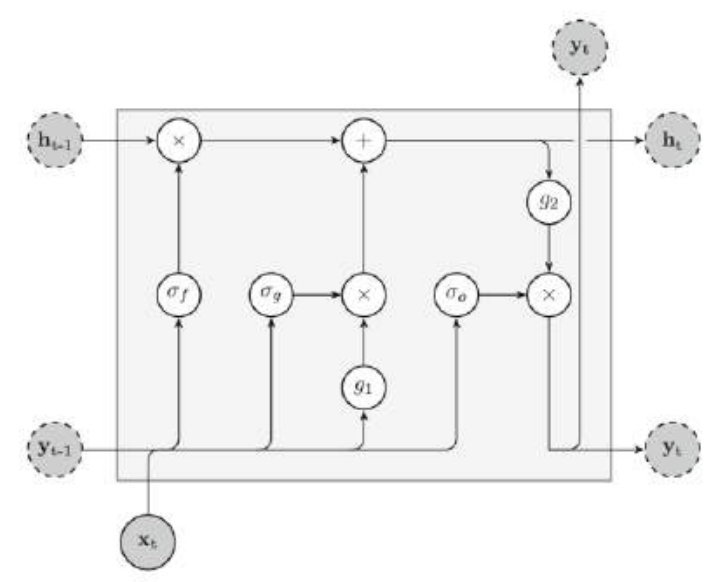

Figure 5 LSTM Architecture Illustration

Figure 6 is an illustration of a commonly used LSTM architecture developed by Graves and Schmidhuber in 2005. The differential equation that defines a forward pass for updating cell state and calculating output is as follows:

$$
\begin{array}{ll}
\text { Forgotten Gate } & : \sigma_{f}[t]=\sigma\left(w_{f} x[t]+R_{f} y[t-1]+b_{f}\right) \\
\text { Candidate status } & : \bar{h}[t]=g 1\left(w_{h} x[t]+R_{h} y[t-1]+b_{h}\right) \\
\text { Update gateway } & : \sigma_{u}[t]=\sigma\left(w_{u} x[t]+R_{u} y[t-1]+b_{u}\right) \\
\text { Cell state } & : h[t]=\sigma_{u}[t] \odot \bar{h}[t]+\sigma_{f}[t] \odot h[t-1] \\
\text { Output gate } & : \sigma_{o}[t]=\sigma\left(w_{o} x[t]+R_{o} y[t-1]+b_{o}\right) \\
\text { Output } & : y[t]=\sigma_{u}[t] \odot \bar{h}[t]+g_{2}(h[t])
\end{array}
$$

$\mathrm{x}[\mathrm{t}]$ is the input vector at time t. Wf, Wh, $\mathrm{Wu}$, and Wo are weight matrices square length applied to the cell input LSTM. Rf, Rh, Ru, and Ro are square matrices that define the weights of repeated connections, while bf, bh, bu, and bo are bias vectors. The function $(\cdot)$ is sigmoid, 1 , while $\mathrm{g} 1(\cdot)$ and $\mathrm{g} 2(\cdot)$ are pointwise non-linear activation functions usually implemented as hyperbolic tangents that suppress the value at $[-1,1]$. Lastly is the entry wise multiplication between two vectors $\odot$ (Hadamard multiplication).

\subsection{Daily Trader}

Stock traders are investors who trade professionally either on their behalf or on behalf of a company. Stock traders who make day trading are called day traders. A day trader conducts buying and selling of stocks for a short period over a particular time, usually within a day. Day trading aims to make small profits from each trade and accumulate those profits over time [10].

Day trading is an activity of buying and selling transactions on the same day to maximize capital gains. Day traders usually use a short-term trading strategy by paying attention to small price movements in liquid and volatile stocks to take advantage of daily stock fluctuations [2], [47]. In addition, day traders avoid holding stocks until tomorrow, assuming tomorrow's uncertainty provides additional risk [47].

\subsection{Price Action Theory}

In general, traders are risk-averse and risk-seeking, a double standard image that expresses aspirations, thoughts, and emotions. Traders avoid risk by processing the information as a reference for decision-making and looking for the chance to get profit opportunities. LSTM 
is a variation of Recurrent Neural Networks (RNN), which is dynamic and allows Machine Learning (ML) modeling on stock data to help make decisions based on past price behavior patterns [3], [22]-[24]

Price action theory was coined by Charles Dow, the father of technical analysis, known as the Dow Theory. Price action theory explains market behavior and focuses on market trends. Prices are the cumulative result of all market information, and market prices discount all of them. Therefore, technical analysis uses price charts and chart patterns in market study analysis. Pure use of price action trading does not use other trading indicators. However, price action analysis and trading indicators are not mutually exclusive.

\section{Results and Discussion}

\subsection{Decision-Making Techniques}

The decision-making technique in the model is the result of the conversion of the LSTM model output in the form of regression into a classification model with additional information on tomorrow's uptrend or downtrend predictions along with tomorrow's forecasts in the form of nominal values and percentages. The features in the decision-making technique model are "Date", "Today's Stock Price", "Tomorrow's Prediction", "Tomorrow's Prediction (\%)", and "Uptrend Prediction". The method used is to reduce the price of "Adj Close" today, $t$ with the predicted result $\hat{t}+1$. The table is an example Decision-Making Techniques using LSTM.

\begin{tabular}{|r|r|r|r|r|r|}
\hline \multicolumn{7}{|c|}{$\begin{array}{c}\text { ANTM 1 March, 2019 to 1 March, } 2020 \\
\text { Today's } \\
\text { Stock } \\
\text { Price }\end{array}$} & $\begin{array}{c}\text { Tomorrow's } \\
\text { Predictions }\end{array}$ & $\begin{array}{c}\text { Tomorrow } \\
\text { Prediction } \\
\text { (\%) }\end{array}$ & \multicolumn{2}{c|}{$\begin{array}{c}\text { Prediction } \\
\text { Difference }\end{array}$} & $\begin{array}{c}\text { Uptrend } \\
\text { Prediction }\end{array}$ \\
\hline $2 / 17 / 2020$ & 671.97 & 12.68 & 1.89 & -22.56 & 1 \\
\hline $2 / 18 / 2020$ & 681.85 & 10.57 & 1.55 & -25.40 & 1 \\
\hline $2 / 19 / 2020$ & 696.68 & 11.83 & 1.70 & -16.77 & 1 \\
\hline $2 / 20 / 2020$ & 701.62 & 12.85 & 1.83 & -2.97 & 1 \\
\hline $2 / 21 / 2020$ & 691.74 & 14.26 & 2.06 & 0.57 & 1 \\
\hline $2 / 24 / 2020$ & 676.91 & 16.96 & 2.51 & 7.74 & 1 \\
\hline $2 / 25 / 2020$ & 652.21 & 15.22 & 2.33 & 14.43 & 1 \\
\hline $2 / 26 / 2020$ & 622.56 & 10.76 & 1.73 & 18.88 & 1 \\
\hline $2 / 27 / 2020$ & 592.92 & 4.49 & 0.76 & 20.22 & 1 \\
\hline $2 / 28 / 2020$ & 568.21 & -1.98 & -0.35 & -7.90 & 0 \\
\hline
\end{tabular}

\subsection{Regression Evaluation}

Table 2 Decision Making Techniques

After modeling and model application, the prediction results of the LSTM model provide varied outputs for each iteration of the model. Table 3 shows the 15 iterations of the LSTM model output period march 1, 2019 to March 1, 2020 before the COVID-19 pandemic and output for the ANTM stock period March 3, 2020 to March 2, 2021 during the COVID-19 pandemic.

ANTM 1 March 2019 to 1 March 2020
\begin{tabular}{r|r|r|r|r|} 
NO & \multicolumn{1}{c}{ R2 } & MAPE & MAE & RMSE \\
\hline 1 & 0.96 & 1.93 & 16.77 & 22.88 \\
\hline 2 & 0.91 & 3.84 & 31.75 & 36 \\
\hline 3 & 0.95 & 2.26 & 19.51 & 25.61 \\
\hline 4 & 0.94 & 2.67 & 23.24 & 30.09 \\
\hline 5 & 0.96 & 2.04 & 17.52 & 23.73 \\
\hline 6 & 0.84 & 5.29 & 42.75 & 47.65 \\
\hline
\end{tabular}

\begin{tabular}{|r|r|r|r|r|}
7 & 0.93 & 2.8 & 23.56 & 30.58 \\
\hline 8 & 0.65 & 8.03 & 66.31 & 69.92 \\
\hline 9 & 0.96 & 2.05 & 17.86 & 24.47 \\
\hline 10 & 0.94 & 2.44 & 20.82 & 28.1 \\
\hline 11 & 0.94 & 2.49 & 21.3 & 28.56 \\
\hline 12 & 0.89 & 4.11 & 32.88 & 39.07 \\
\hline 13 & 0.95 & 2.27 & 20.15 & 27.55 \\
\hline 14 & 0.94 & 2.43 & 21.24 & 27.9 \\
\hline 15 & 0.96 & 2.17 & 18.41 & 24.09 \\
\hline
\end{tabular}




\begin{tabular}{|c|c|c|c|c|}
\hline \multicolumn{5}{|c|}{ ANTM 2 March 2020 to 2 March 2021} \\
\hline NO & $\begin{array}{c}\mathrm{R} 2 \\
\text { SCORE }\end{array}$ & MAPE & MAE & RMSE \\
\hline 1 & 0.97 & 6.39 & 81.32 & 138.64 \\
\hline 2 & 0.97 & 6.13 & 82.48 & 135.21 \\
\hline 3 & 0.98 & 10.61 & 89.66 & 117 \\
\hline 4 & 0.97 & 7.13 & 89.41 & 148.5 \\
\hline 5 & 0.95 & 18.01 & 144.61 & 173.25 \\
\hline 6 & 0.98 & 11.82 & 99.88 & 123.18 \\
\hline 7 & 0.95 & 13.18 & 129.61 & 181.63 \\
\hline
\end{tabular}

\begin{tabular}{|r|r|r|r|r|}
8 & 0.98 & 9.27 & 81.78 & 110.67 \\
\hline 9 & 0.98 & 5.12 & 69.37 & 126.68 \\
\hline 10 & 0.97 & 10.52 & 95.09 & 130.87 \\
\hline 11 & 0.97 & 10.08 & 95.48 & 134.97 \\
\hline 12 & 0.97 & 10.37 & 102.34 & 148.43 \\
\hline 13 & 0.98 & 5.06 & 58.4 & 101.57 \\
\hline 14 & 0.98 & 5.93 & 62.49 & 102.26 \\
\hline 15 & 0.97 & 8.94 & 95.25 & 144.35 \\
\hline
\end{tabular}

Table 3 ANTM Regression Evaluation

Figure 7 shows the best prediction iteration graphic model before COVID-19, and figure 8 shows the best prediction iteration graphic model during the pandemic. The iteration prediction output showed the highest R2 Score of 98\% during the COVID-19 pandemic and 96\% before the COVID-19 pandemic. The two R2 Score values indicate that the model has successfully explained the movement of ANTM's shares. The best risk before the COVID pandemic showed MAPE 1.93\%, MAE Rp. 16.77, and RMSE Rp. 22.88 lower than the best predictions during the COVID-19 pandemic risk of MAPE 5.06\%, MAE Rp 58.40, and RMSE Rp. 104.91. Based on the regression evaluation, predictions using LSTM on ANTM shares before the COVID-19 pandemic had a lower risk than during the COVID 19 pandemics. Using price as the sole predictor, the LSTM model succeeded in predicting ANTM's stock prices in both conditions before and during the COVID-19 pandemic.

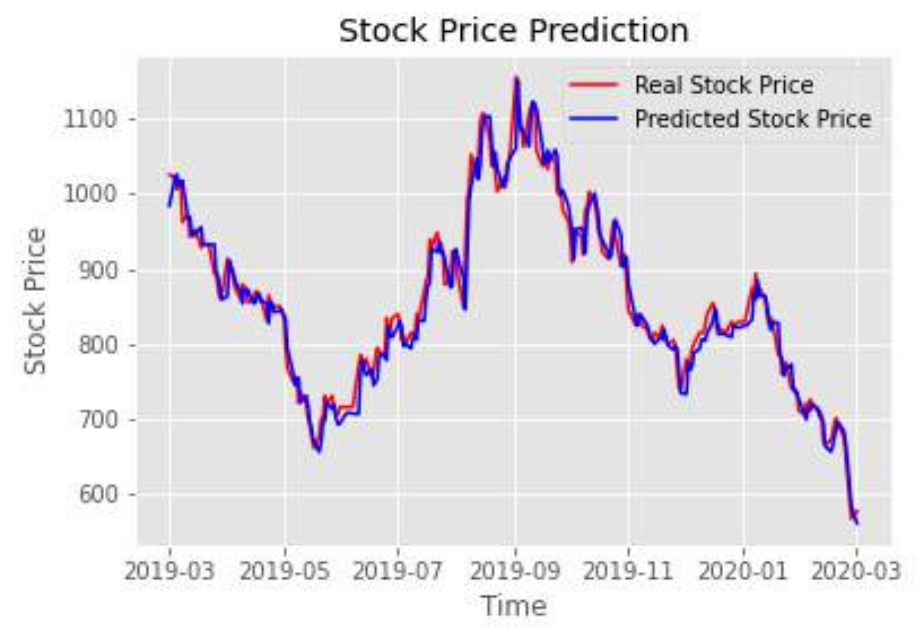

Figure 6 Iteration 1 ANTM March 1, 2019 to March 1, 2020 (Before Covid-19) 


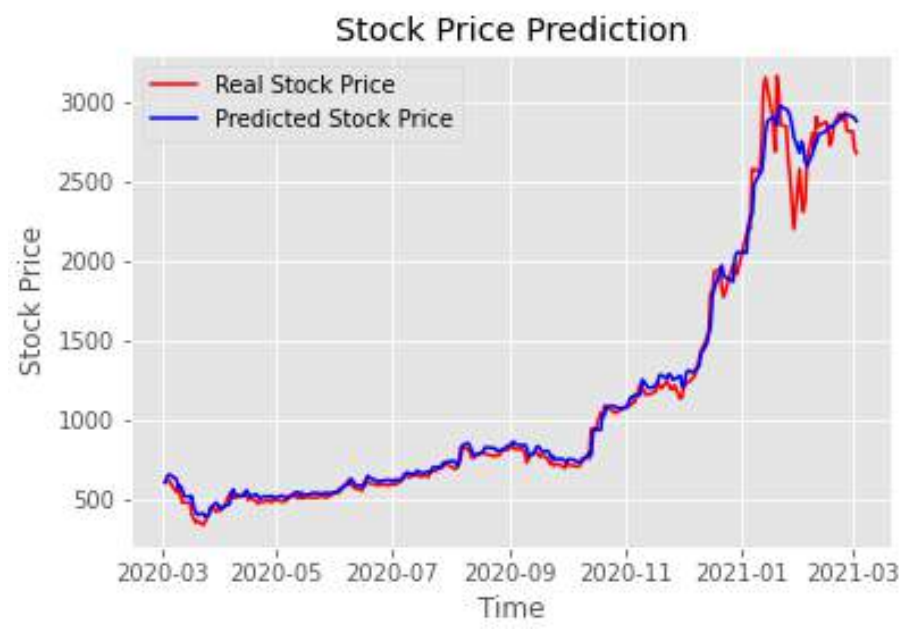

Figure 7 Iteration 13 ANTM March 2, 2020 to March 2, 2021 (During Covid-19)

\subsection{Classification Evaluation}

Table 4 results from evaluating the LSTM model from 15 iterations of the model before and during the COVID-19 pandemic. The evaluation results show that the output varies from one iteration to another. For example, the best evaluation for the model before the COVID-19 pandemic has an AUC value of $55 \%$, F1 Score $74 \%$, Recall $100 \%$, Precision $66 \%$, and Accuracy $58 \%$. While for the best evaluation, the model during the COVID-19 pandemic has an AUC value of $55 \%$, F1 Score $67 \%$, Recall $100 \%$, Precision $78 \%$, and Accuracy $55 \%$.

The evaluation of the F1 Score and Accuracy classification on the LSTM model before the COVID-19 pandemic was superior to during the COVID-19 pandemic. Recall, and AUC evaluation of the model before and during the COVID-19 pandemic showed comparable values, while in the Precision evaluation, the model during the COVID-19 was superior the model before COVID-19.

\begin{tabular}{|c|c|c|c|c|c|}
\hline \multicolumn{6}{|c|}{$\begin{array}{l}\text { Evaluation ANTM March 1, } 2019 \text { to March } \\
\qquad 12020\end{array}$} \\
\hline NO & AUC & $\mathrm{F} 1$ & REC & PREC & ACC \\
\hline 1 & 0.51 & 0.67 & 0.79 & 0.58 & 0.55 \\
\hline 2 & 0.50 & 0.00 & 0.00 & 0.00 & 0.42 \\
\hline 3 & 0.50 & 0.69 & 0.84 & 0.58 & 0.56 \\
\hline 4 & 0.51 & 0.74 & 1.00 & 0.58 & 0.58 \\
\hline 5 & 0.52 & 0.47 & 0.38 & 0.60 & 0.50 \\
\hline 6 & 0.50 & 0.04 & 0.02 & 0.50 & 0.42 \\
\hline 7 & 0.51 & 0.54 & 0.50 & 0.59 & 0.51 \\
\hline 8 & 0.00 & 0.00 & 0.00 & 0.00 & 0.42 \\
\hline 9 & 0.51 & 0.62 & 0.66 & 0.58 & 0.53 \\
\hline 10 & 0.48 & 0.58 & 0.60 & 0.56 & 0.50 \\
\hline 11 & 0.50 & 0.57 & 0.56 & 0.57 & 0.51 \\
\hline 12 & 0.53 & 0.32 & 0.21 & 0.66 & 0.48 \\
\hline 13 & 0.52 & 0.73 & 0.95 & 0.59 & 0.58 \\
\hline 14 & 0.50 & 0.73 & 1.00 & 0.57 & 0.57 \\
\hline 15 & 0.55 & 0.45 & 0.34 & 0.65 & 0.51 \\
\hline
\end{tabular}

\begin{tabular}{|c|c|c|c|c|c|}
\hline \multicolumn{6}{|c|}{$\begin{array}{c}\text { Evaluation ANTM } 2 \text { March } 2020 \text { to } 2 \\
\text { March } 2021\end{array}$} \\
\hline $\mathrm{NO}$ & AUC & $\mathrm{F} 1$ & REC & PREC & ACC \\
\hline 1 & 0.51 & 0.67 & 1.00 & 0.50 & 0.50 \\
\hline 2 & 0.50 & 0.64 & 0.93 & 0.49 & 0.49 \\
\hline 3 & 0.52 & 0.25 & 0.16 & 0.59 & 0.53 \\
\hline 4 & 0.50 & 0.49 & 0.48 & 0.50 & 0.50 \\
\hline 5 & 0.52 & 0.33 & 0.24 & 0.53 & 0.52 \\
\hline 6 & 0.50 & 0.64 & 0.91 & 0.49 & 0.50 \\
\hline 7 & 0.51 & 0.44 & 0.39 & 0.51 & 0.51 \\
\hline 8 & 0.55 & 0.63 & 0.80 & 0.52 & 0.54 \\
\hline 9 & 0.51 & 0.46 & 0.43 & 0.50 & 0.51 \\
\hline 10 & 0.51 & 0.39 & 0.32 & 0.50 & 0.51 \\
\hline 11 & 0.50 & 0.40 & 0.34 & 0.49 & 0.50 \\
\hline 12 & 0.52 & 0.43 & 0.37 & 0.52 & 0.52 \\
\hline 13 & 0.55 & 0.22 & 0.13 & 0.78 & 0.55 \\
\hline 14 & 0.53 & 0.31 & 0.21 & 0.59 & 0.54 \\
\hline 15 & 0.50 & 0.42 & 0.37 & 0.49 & 0.50 \\
\hline
\end{tabular}

Table 4 ANTM Classification

\subsection{Best Model Selection}

In this study, the author selects the best model based on the minimum criteria of Accuracy above 51\% and R2 Score above 71\%, which indicates the model shows stock performance moves relatively in line with the index. The author's criteria are based on [33] 
opinion. [33] argues that the R2 Score with a value of $70 \%$ or less generally indicates that it does not follow the movement of the index. So statistically, the best LSTM model before the COVID-19 pandemic was in iteration IV. Meanwhile, the best LSTM model during the COVID19 pandemic was in iteration XIII. However, the selection of the suitable model depends on the taste and trading style of the trader.

In addition to using the R2 Score or Accuracy reference, traders can use other evaluation models as a reference in determining risk criteria. AUC Score can be used as a reference that shows the probability of randomness. MAPE, MAE and RMSE refer to the error of the actual value compared to the predicted value. Precision as a reference for the accuracy of the model predicting uptrend issuers, recall as a comparison of the uptrend ratio with positive overall predictions to describe the level of sensitivity, and F1 Score as a reference for the harmonic mean between precision and recall.

Based on the study results in table 4, the decision-making technique model using LSTM has the best accuracy rate of $58 \%$. This result means that this model has a $42 \%$ error risk rate that must be appropriately managed. Accuracy in trading is essential but not everything. Even a model with high accuracy will still be a problem if it has an accuracy rate of up to $99 \%$ but loses everything in a $1 \%$ trading error.

Traders must understand their risk criteria trading model and its limitations. For example, the model in this study does not provide technical information on price movement analysis, candlesticks or is used to predict more than one day in the long term. Thus, it can be understood that the manufacturing technique using LSTM can provide sufficient decisionmaking information to a certain extent, especially when compared to baseless speculation such as "gambling". Traders must be aware that speculating in the stock market can be fun or even profitable if traders win but very risky.

No professional trader has a $100 \%$ or perfect accuracy record. In an interview, Steven Cohen, a top American trader who is also known as one of the top 10 world-famous traders of all time, explained that he only has $63 \%$ accuracy on his best trades, and most traders only have an accuracy of $50 \%$ to $55 \%$. That is why Steven Coven recommends managing the most negligible possible losses from each trade and becoming a winner with more significant gains. For success, traders need discipline and implement strategies provided that the rules place the right opportunities through a thorough process, consideration of safety from losses, and adequate returns. So that it can be concluded, the use of the LSTM method can be used as a technique for making buying and selling decisions for daily traders, especially if it is maximized with the right combination of strategies such as technical analysis, stop loss, financial management, emotions, risks, etc.

\section{Conclusions}

Based on the research that has been done, the following conclusions can be drawn:

a) The LSTM model can predict stock prices well using historical stock prices as the sole predictor.

b) The LSTM model can be used as a trading decision-making technique for day traders.

c) The risk of stock prediction using the LSTM method in 2019 before the COVID pandemic was proven to be lower than in 2020 during the COVID pandemic.

For further research, researchers can conduct more in-depth research on the risk criteria for making trading decisions as an essential reference that can be used to select the LSTM model.

\section{References}

[1] A. Yadav, C. K. Jha, and A. Sharan, "Optimizing LSTM for time series prediction in Indian stock market," in Procedia Computer Science, 2020, vol. 167, doi: 10.1016/j.procs.2020.03.257.

[2] S. I. Song, E. Y. Chu, and T. S. Lai, "Characteristics and strategies of a consistently profitable proprietary day trader at bursa Malaysia," Manag. Account. Rev., vol. 17, no. 3, pp. 109-129, 2018, [Online]. Available: doi: 10.24191/mar.v17i3.818.

[3] S. Yao, L. Luo, and H. Peng, "High-Frequency Stock Trend Forecast Using LSTM Model," in 2018 13th International Conference on Computer Science \& Education (ICCSE), Aug. 2018, pp. 1-4, doi: 10.1109/ICCSE.2018.8468703.

[4] R. Hidayat, "Prediksi Harga Saham Menggunakan Neural Network," vol. 5, no. 1, pp. 64- 
72, 2016.

[5] J. F. Carter, Mastering the Trade: Proven Techniques for Profiting from Intraday and Swing Trading Setups. McGraw-Hill Education, 2019.

[6] A. D. Gintings, P. P. Sjahir, Y. Ramadhan, and A. A. Madjid, "Waspada Investasi Saham Pompom! - YouTube," detikcom, 2021. https://www.youtube.com/watch?v=HYmg0clbr40\&ab_channel=detikcom (accessed Jan. 29, 2021).

[7] E. Wahyono, "Kapan Sebenarnya Corona Pertama Kali Masuk RI?," kompas, 2020. https://news.detik.com/berita/d-4991485/kapan-sebenarnya-corona-pertama-kalimasuk-ri (accessed May 30, 2021).

[8] Ihsanuddin, "Presiden Jokowi Teken Keppres Tetapkan Wabah Covid-19 Bencana Nasional," KOMPAS, 2020. https://nasional.kompas.com/read/2020/04/13/18101841/presiden-jokowi-tekenkeppres-tetapkan-wabah-covid-19-bencana-nasional (accessed May 30, 2021).

[9] I. Puspitasari, "Saham-saham ini naik fantastis di masa pandemi, simak rekomendasi analis berikut," KONTAN, 2021. https://investasi.kontan.co.id/news/saham-saham-ininaik-fantastis-di-masa-pandemi-simak-rekomendasi-analis-berikut (accessed May 30, 2021).

[10] C. Nauvall, Trade like A Stock Market Wizard: How to achieve super performance in stocks in any market, Kindle Edi. 2021.

[11] Y. Hu, J. Ni, and L. Wen, "A hybrid deep learning approach by integrating LSTM-ANN networks with GARCH model for copper price volatility prediction," Phys. A Stat. Mech. its Appl., vol. 557, 2020, doi: 10.1016/j.physa.2020.124907.

[12] Bursa Efek Indonesia (BEI), "Press Release No: 114/BEI.SPR/12-2020," Bursa Efek Indonesia, 2020. https://www.idx.co.id/berita/press-release-detail/?emitenCode $=1444$ (accessed Mar. 01, 2021).

[13] F. N. Ulya, "Investor Pemula, Hati-hati Fenomena 'Pompom' Saham," Kompas.com, 2021. https://money.kompas.com/read/2021/02/27/181400126/investor-pemula-hatihati-fenomena-pompom-saham (accessed Oct. 03, 2021).

[14] I. F. Ramadhansari, "Era Influencer Main Saham, Waspada Pom-pom," market.bisnis.com, 2021. https://market.bisnis.com/read/20210106/7/1339462/erainfluencer-main-saham-waspada-pom-pom (accessed Feb. 01, 2021).

[15] R. Filbert, Bandarmology: Membeli Saham Gaya Bandar Bursa, 2nd ed. PT Elex Media Komputindo, 2016.

[16] G. Madaan and S. Singh, "An analysis of behavioral biases in investment decisionmaking," Int. J. Financ. Res., vol. 10, no. 4, pp. 55-67, 2019, doi: 10.5430/ijfr.v10n4p55.

[17] B. Umoru, P. I. Udobi-Uwolaja, G. U. Zekwe, W. C. Iyiegbuniwe, and J. E. Ezike, "Are stock returns predictable? The myth of efficient market hypothesis and random walk theory using Nigerian market data," Int. J. Econ. Bus. Manag. Res., vol. 4, no. 7, pp. 115-130, 2020.

[18] Y. Wang, Y. Liu, and L. Li, "Short-term Stock Forecasting based on Fractal and Chaos Theory," vol. 8, no. 2, pp. 109-116, 2021.

[19] I. Klioutchnikov, M. Sigova, and N. Beizerov, "Chaos Theory in Finance," Procedia Comput. Sci., no. 119, pp. 368-375, 2017.

[20] R. Sahni, "Analysis of Stock Market Behaviour by Applying Chaos Theory," in 2018 9th International Conference on Computing, Communication and Networking Technologies (ICCCNT), Jul. 2018, pp. 1-4, doi: 10.1109/ICCCNT.2018.8494103.

[21] M. Waisi, "Advantages and disadvantages of ai based trading and investing versus traditional methods," Tampere University of Applied Sciences, 2020.

[22] A. Fauzi, "FORECASTING SAHAM SYARIAH DENGAN MENGGUNAKAN LSTM," AlMasraf J. Lemb. Keuang. dan Perbank., vol. 4, no. 1, 2019, doi: 10.15548/almasraf.v4i1.235.

[23] T. Laurent and J. von Brecht, "A recurrent neural network without chaos," Dec. 2016, [Online]. Available: http://arxiv.org/abs/1612.06212.

[24] M. Madondo and T. Gibbons, "Learning and Modeling Chaos Using LSTM Recurrent Neural Networks," MICS 2018 Proc., pp. 1-14, 2018, [Online]. Available: http://micsymposium.org/mics2018/proceedings/MICS_2018_paper_26.pdf.

[25] T. R. Silva, A. W. Li, and E. O. Pamlona, "Automated Trading System for Stock Index 
Using LSTM Neural Networks and Risk Management," 2020 Int. Jt. Conf. Neural Networks, pp. 1-8, 2020, doi: DOI:10.1109/IJCNN48605.2020.9207278.

[26] S. Rehman, I. U. Chhapra, M. Kashif, and R. Rehan, "Are Stock Prices a Random Walk? An Empirical Evidence of Asian Stock Markets," Etikonomi, vol. 17, no. 2, pp. 237-252, 2018, doi: 10.15408/etk.v17i2.7102.

[27] B. Iván and N. Zsolt, "Random Walk, Ergodicity versus Predictability - The Case of the Budapest Stock Exchange," Adv. Econ. Bus., vol. 4, no. 4, pp. 165-181, 2016, doi: 10.13189/aeb.2016.040403.

[28] J. Felton and P. Jain, "True Returns: Adjusting Stock Prices for Cash Dividends and Stock Splits,' Advances in Financial Education, Summer 2019, 192-205.," vol. 17, no. March, pp. 192-205, 2019.

[29] V. Kotu and B. Deshpande, Data Science: Concepts and Practice, 2nd ed. Cambridge: Jonathan Simpson, 2019.

[30] S. Tiwari, "Activation functions in Neural Networks," geeksforgeeks.org, 2020. https://www.geeksforgeeks.org/activation-functions-neural-networks/ (accessed May $27,2021)$.

[31] U. Michelucci, Applied Deep Learning. Berkeley, CA: Apress, 2018.

[32] J. W. G. Putra, Pengenalan Konsep Pembelajaran Mesin dan Deep Learning. Self Publised, 2020.

[33] J. Fernando, "R-Squared Definition," investopedia.com, 2020. https://www.investopedia.com/terms/r/r-squared.asp (accessed May 27, 2021).

[34] A. Bhandari, "AUC-ROC Curve in Machine Learning Clearly Explained," analyticsvidhya.com, 2020. https://www.analyticsvidhya.com/blog/2020/06/auc-roccurve-machine-learning/ (accessed May 27, 2021).

[35] C. C. Aggarwal, Neural Networks and Deep Learning. Cham: Springer International Publishing, 2018.

[36] F. M. Bianchi, E. Maiorino, M. C. Kampffmeyer, A. Rizzi, and R. Jenssen, Recurrent Neural Networks for Short-Term Load Forecasting. Cham: Springer International Publishing, 2017.

[37] N. K. Manaswi, Deep Learning with Applications Using Python. 2018.

[38] S. Skansi, Introduction to Deep Learning. Cham: Springer International Publishing, 2018.

[39] A. Arfan and E. T. P. Lussiana, "Perbandingan Algoritma Long Short-Term Memory dengan SVR Pada Prediksi Harga Saham di Indonesia," PETIR, vol. 13, no. 1, 2020, doi: $10.33322 /$ petir.v13i1.858.

[40] A. Arfan and E. T. P. Lussiana, "Prediksi Harga Saham Di Indonesia Menggunakan Algoritma Long Short-Term Memory," SeNTIK, vol. 3, no. 1, pp. 225-230, 2019.

[41] S. S. Namin, "Forecasting economic and financial time series: Arima vs. LSTM," arXiv. 2018.

[42] D. M. Q. Nelson, A. C. M. Pereira, and R. A. De Oliveira, "Stock market's price movement prediction with LSTM neural networks," in Proceedings of the International Joint Conference on Neural Networks, 2017, vol. 2017-May, doi: 10.1109/IJCNN.2017.7966019.

[43] H. Niu, K. Xu, and W. Wang, "A hybrid stock price index forecasting model based on variational mode decomposition and LSTM network," Appl. Intell., vol. 50, no. 12, pp. 4296-4309, Dec. 2020, doi: 10.1007/s10489-020-01814-0.

[44] K. Pawar, R. S. Jalem, and V. Tiwari, "Stock Market Price Prediction Using LSTM RNN," in Advances in Intelligent Systems and Computing, 2019, vol. 841, doi: 10.1007/978981-13-2285-3_58.

[45] F. Qian and X. Chen, "Stock prediction based on LSTM under different stability," 2019, doi: 10.1109/ICCCBDA.2019.8725709.

[46] M. Rana, M. M. Uddin, and M. M. Hoque, "Effects of activation functions and optimizers on stock price prediction using LSTM recurrent networks," 2019, doi: 10.1145/3374587.3374622.

[47] S. U. Ady, A. Mulyaningtyas, and I. Faida, "Overconfidence: technical analysis in trading, investment or gambling?," CIFET, 2019, [Online]. Available: DOI 10.4108/eai.21-92019.2293942\%0A. 